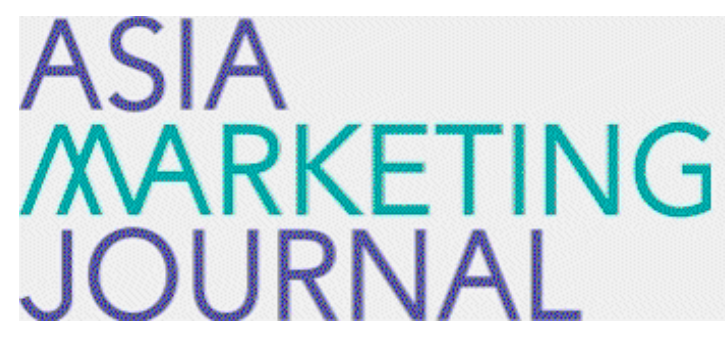

ASIA MARKETING JOURNAL

Volume 16 | Issue 4

Article 7

$1-31-2015$

\title{
Aekyung : Design Innovation on New Product Development
}

Changjo Yoo

Kyungdo Park

Yeonjin Cho

Follow this and additional works at: https://amj.kma.re.kr/journal

Part of the Marketing Commons

\section{Recommended Citation}

Yoo, Changjo; Park, Kyungdo; and Cho, Yeonjin (2015) "Aekyung: Design Innovation on New Product Development," Asia Marketing Journal: Vol. 16 : Iss. 4 , Article 7.

Available at: https://doi.org/10.15830/amj.2015.16.4.89

This Article is brought to you for free and open access by Asia Marketing Journal. It has been accepted for inclusion in Asia Marketing Journal by an authorized editor of Asia Marketing Journal. 


\title{
Aekyung: \\ Design Innovation on New Product Development
}

\author{
Changjo Yoo* \\ Kyungdo Park** \\ Yeonjin $\mathrm{Cho}^{* * *}$
}

Because of fierce competition, the importance of product design has been emphasized. In this case study of Aekyung, we mainly focus on this company's efforts to incorporate design innovation into new product development process. Their efforts on innovative product design turn out to be rewarding as the sales and market share soar. Through this case, we try to identify what aspects of Aekyung's efforts lead to the better and more innovative product design.

Key words: product design, package, innovation, communication

\section{Introduction}

Product design has become one of the most important factors for the success of new product in consumer market of late (Ravasi and Stiglianni, 2012; Swan, Kotabe, and Allred 2005). Until the early part of 1990s, it was primarily the price and the function that triggered consumers to decide which product they would like to purchase. However, severe competition has changed the market itself. Consumers not only take the price and the function into account, but also they search for products with a good, innovative design. A company with a dominant design capacity, in other words, can survive and even prosper in market. However, it needs to be noted that consumers do not seem to look for a nice appearance only. What consumers require, in fact, is the innovation in design. This explains various ways in which an innovative design becomes one of the most deciding aspects of success for a new product launch. Also, this tells us why an innovative

\footnotetext{
* Professor of Marketing at Dongguk University-Seoul(yoo@dongguk.edu)

** Associate Professor of Marketing at Sogang University(kyungdo@sogang.ac.kr), Corresponding author

*** Ph.D. candidate in Marketing at Sogang University(jyj733679@gmail.com)
} 
design becomes very fundamental for a new product development.

Aekyung(AK thereafter), whose management philosophy has been defined as creativity and communication, appears to have recognized the role of design in consumer market. In response to this trend in consumer market, they opened a design center near Hongik University in 2007. The center carries out the same management philosophy of AK, namely, creativity and communication, while beginning to actively and rigorously involve AK's product design process. It is not surprising at all that the new products that were created by the center led the market of various categories. Their hair care products (Kerasys Perfume Shampoo), laundry liquid detergent ( $\mathrm{LiQ})$, and household gift sets are excellent examples. These examples are more meaningful because the success of these products was coincided with the decline of consumer's demand of these products due to economic recession.

LiQ is sold in a new package that is attractive, handy, neat, and easy to store and use. This product is now the leader in liquid detergent market. The household gift sets also provide an interesting case to take a look. In fact, before 2007, AK failed to differentiate their household gift sets from competing products. Moreover, because of the nature of the products that is extremely sensitive to economic downturn and price, the overall sales of the bath item gift sets was declining. Despite the decrease, top executives showed constant support for the design improvement, allowing the center being able to create package designs that appeal to the consumers' emotion and sensibility. This, in turn, distinguishes AK's products from the others, beginning to receive support from the consumers.

This study fist attempts to explain AK's design management activities using industrial design development model. After explaining AK's overall design management, we turn to the specific cases: product development of LiQ and bath item gift sets. Using these two cases, we would like to demonstrate the importance of product design in the success of the new product. AK's cases, at the same time, will provide a good reference for other companies to consider.

\section{Design Management Model}

Both marketing researchers and practitioners have recognized the importance of design management. This study utilizes the model of 'Input for new ideas in industrial design' proposed by J. Gotzsch(1999) to discuss the importance of design orientation in new product development process. Gotzsch's model has examined input factors of successful design management for a new product development. The model classifies the input factors in two: internal or external environmental factors. While 
external factors refer to cultural value, competition, and user, internal factors include management, technology, and company culture. These six factors enable the company to sharpen its design skills and in turn lead to superior NPD performance. In the following discussion, we list both external and internal factors, illustrating what AK does with each factor.

\subsection{External Factors}

First, good design, in one way another, reflects the cultural value of the society. Social and environmental concerns have become increasingly important these days, and they are gradually influential in behavioral change of consumers. Companies cannot avoid listening to environmental concerns any longer. They needed to take these concerns into account as they develop new products. Air pollution and overall wellbeing of consumers, for example, are two major concerns that current society addresses. Recent products, regardless of their categories, all show they responded to these concerns.

Aekyung, one of the companies with an image of an eco-friendly corporation, is continuously making an effort to produce eco-friendly product through carbon reduction activities. For example, AK has tried to minimize carbon emission by reducing package waste. Also, they have succeeded to develop a detergent that consumers use lesser without scarifying cleansing power. As a result of commitment to the low-carbon green growth, AK was awarded 'Contribution to a Low-Carbon Green Growth by Prime Minister' in 2012, and selected as a company who got 'Green product of the Year'. LiQ received Minister Award from Ministry of Knowledge Economy in the category of Green Management.

Second, higher competition is an important impetus for a good design. A number of rival companies sprung up and competed desperately to differentiate their new product from the competitors. To survive in the marketplace, products have to equip with an innovative, excellent product design along with high quality and competitive price.

Companies compete one another in two directions: price and non-price competition. AK seems to compete in both directions. AK has sold products at reasonable price from the consumer's perspective (e.g., launched low price gift sets, promoted limited special offer) so as to have an edge in price competitiveness. Also, AK has put efforts to improve product and package design. They invest their resource on advertising, displaying, and packaging.

Third, good design needs to suit the users. When companies develop new products design, they tend to improve the design of products according to the noticeable features of existing products. In this process, they examine consumers' past buying pattern. More specifically, the following major elements have been taken into account for new product development: how 
products can satisfy customer need, what product features can be useful and effective to customers. Such user-oriented design approach tends to increase the overall value of the product in market.

AK tried to combine an exquisite design with flawless functionality, seeking to meet consumers' need. In order to do so, they always try to listen to what consumers say. The company selected a group of housewives who represent the end users for household items, listening to what they had to say about a new product. For example, AK observed this group carefully, finding out that they complained about the weight of liquid detergent. Also, AK, through this group, has learned that consumers feel inconvenience when the liquid detergent is dripping down or spilling over. Consumers had difficulties to measure how much detergent they needed. In order to solve these problems, AK develops a cap that can function both as a washing ball and measuring cup, leading the consumers to use the proper amount of the detergent.

\subsection{Internal Factors}

Aekyung, in Chinese, literally means 'love' and 'respect'. Ever since AK has established itself in 1954, these two have been working as the core values of the company. However, these two go beyond mere values of AK that they cherished, but they have been realized in al- most every practical aspect of AK's management process. In implementing these values in practice, AK associated them with their management philosophy, that is, creativity and communication, thereby creativity and communication being encouraged and supported on the basis of love and respect.

In their human resource management, for example, AK valued creativity and communication on employees' parts. Definitely, creativity and communication are highly fundamental in developing innovative design. Also, AK has been extremely supportive for educating professional brand managers and personnel of marketing department. AK has begun sharing common ground between marketers and 'Loyal AK Man' from other departments so that they can be frequently involved in collaborative activity. Third, AK has conducted Strategic marketing meeting, Product development meeting, Brand review meeting, and Tea time run by top management. This hands-on management approach was helpful for effectiveness of decision making. Top management's support for the new product development projects is likely to remove barriers when they enter a completely new market or release a new product. This leads the new product development team to willingly take risk when they create innovative product. Similarly, top management can propose the employees' explicit goals. Such supports from top management sometimes provide a strong motivation to pursue the goal. 
In order to develop a better, innovative design, AK invested and established infrastructure as well. In 2007, AK has established their own design center at Hongik University area in Seoul, one of the hottest spots for young generations. The area is best known for stylish fashions and contemporary art works. The decision to set up the design center at the area was made by top managements who completely understand the significance of design function in their business. In this design center, all the product development related departments are relocated. This setting creates more efficient communications of employees as needed.

Finally, AK noted that an innovative design cannot be realized if technology is not able to support it. In other words, an innovative design goes in tandem with innovative technology. The members of AK's Design Center consist of personnel from package development team and creative design team. While the former was aware of every details of design even at the initial stage of product development, providing and proposing practical advices, the latter involves the entire process of product development and marketing, suggesting and implementing innovative design ideas. Here, again, the company's value of creativity and communication are realized at a practical level.

\section{Aekyung Case}

\subsection{Company Background}

Aekyung Fat and Oil Industry Co., Ltd was found in June 1954 as a soap making business by the founder, Mongin Chae with about 50 full-time employees. When AK first established the company right after the Korean War, they started to sell soaps and detergents. AK's household items including soap and detergent are still dominant products in their respective market. Figure 1 shows AK's household products mix, consisting of four product lines: laundry detergent, dish detergent, dental care, and hair care. Each product line includes a number of brands, while these brands lead the respective market in terms of its market share and brand power.

AK has entered not only the consumer goods industry for common or daily use but also chemical industry, department store, and the airline industry, expanding its capacity to create various types and forms of products and services. AK had a historic year with 5,000 billion won in the total sales in 2013. Today, it is named among the best 50 Korea companies. More importantly, it is one of the best 50 Korea companies led by woman CEO, Youngshin Jang whose leadership resonates well with the company's value of love and respect.

As we pointed out earlier, the company's value 
〈Figure 1〉 AK's household products mix

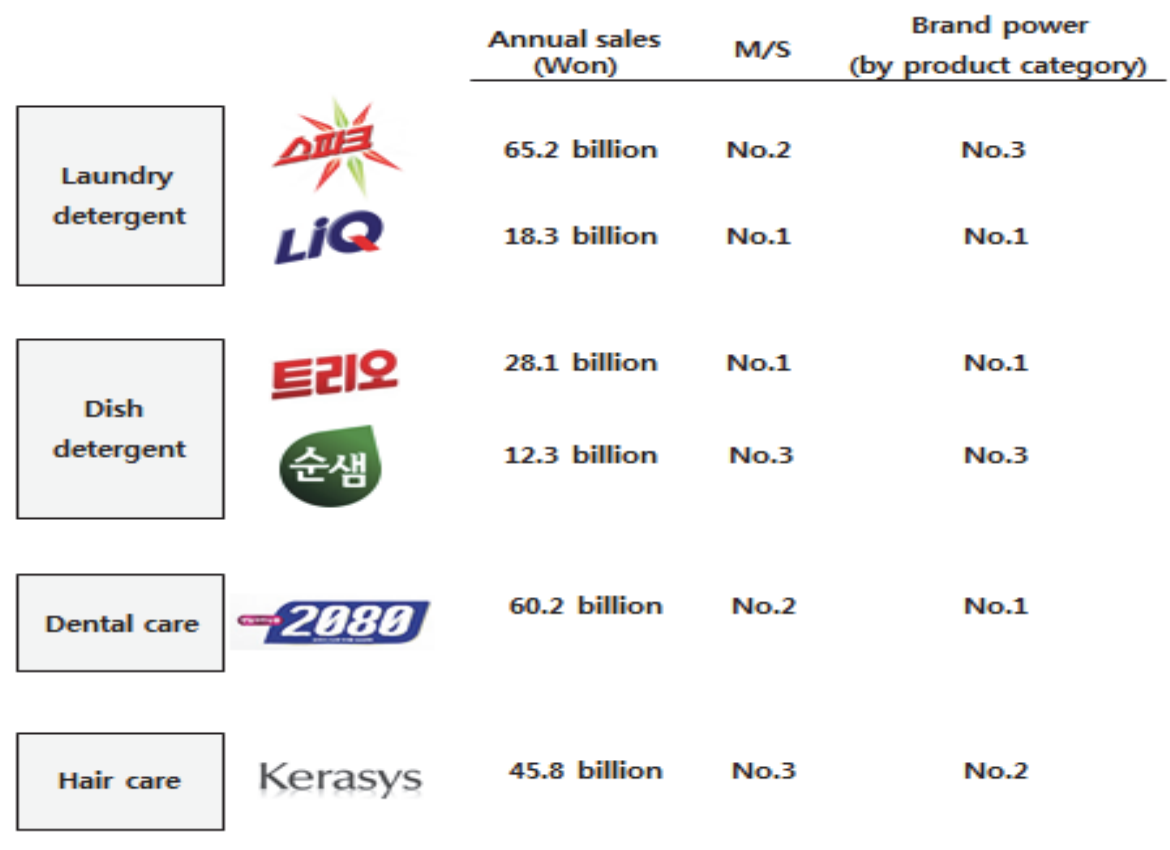

of love and respect are the foundation for AK's $3.2 \mathrm{LiQ}$

human recourse management. On the basis of these values, the ideas of innovative new product and new business model were proposed and realized. In this case study, we mainly focus on AK's innovation efforts on product design. Innovative product design is one of the key success factors for AK's survival and success for last 50 years.

The following discussion focuses upon the development of two products, namely, $\mathrm{LiQ}$ and gift sets, demonstrating the importance of product design on AK's part in the success of these two products.

\subsubsection{Market Situation of Laundry Detergent}

The domestic laundry detergent market can be divided into three types: enzyme detergent, concentrated powder detergent, and liquid detergent.1) Figure 2 shows that these three types of detergent coexist in the market since 1990s with the liquid type as the latecomer. Also this figure illustrates that market share of each type has changed in the course of time, thereby the liquid being the most preferable by

1) LiQ is known for utilizing various types of enzymes including Protease and Lactase that make easy to remove heavy stain and dirt. 
〈Figure 2〉 Trend of domestic laundry detergent market

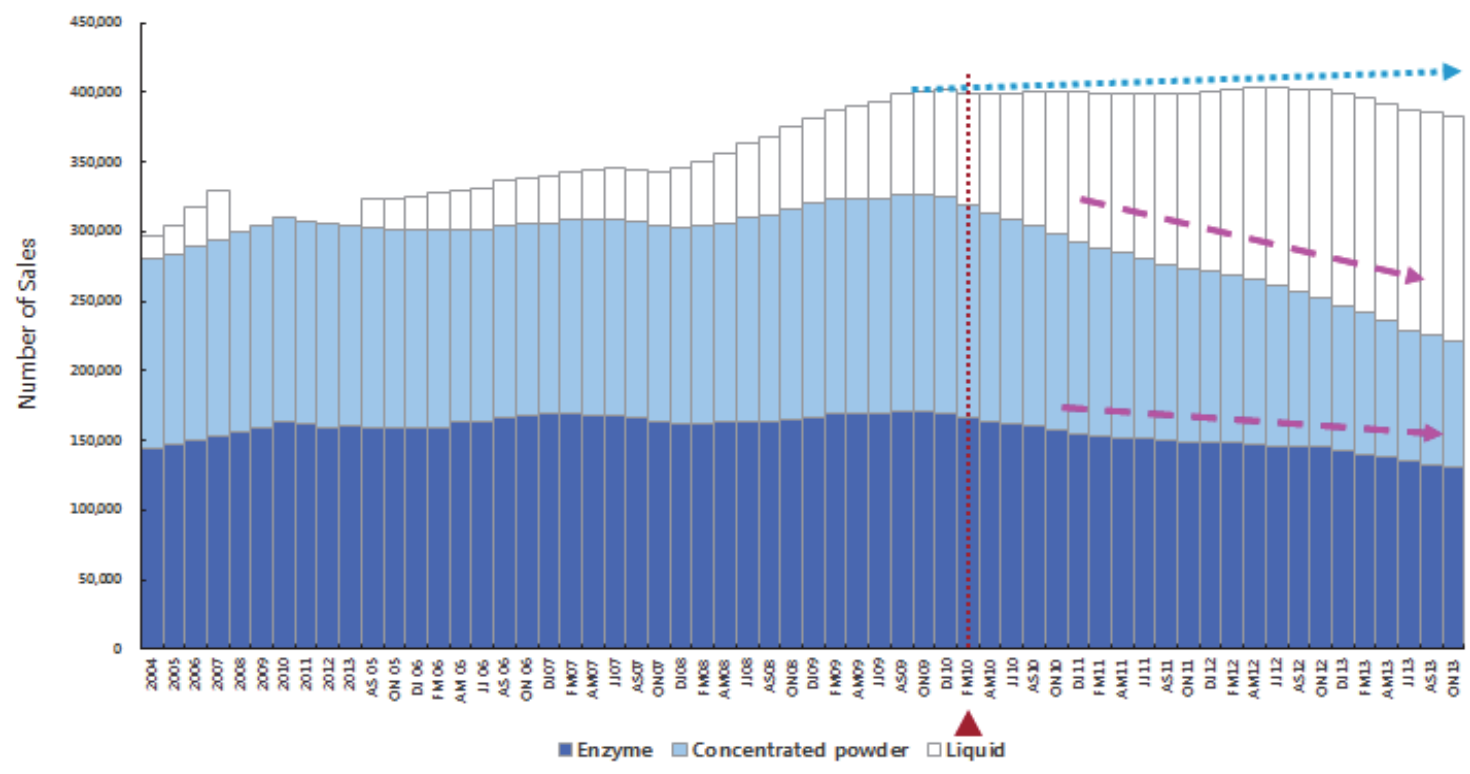

2014. Interestingly, one of the reasons why the liquid and concentrated type was more popular among consumers had to do with the fact that the enzyme detergent was accused to trigger water pollution. Despite the expansion of the market for the enzyme detergent, there was growing recognition that customers admired more environmentally-friendly new products, which, in turn, has changed the industry trend.

AK, along with LG Household \& Health Care Ltd who was known for the detergent, Tech, has been the leading company for the liquid detergent market. The market for the liquid detergent has been growing, marking 25.7\%, $30.7 \%$, and $35.7 \%$ of the total detergent market of 2011, 2012, and 2013 respectively. Of 25.7\% of liquid detergent market share, AK occupied 20.1\%. In 2013, this number $20.1 \%$ has in- creased to $22.6 \%$.

\subsubsection{New Product Development Process of $L i Q$}

LiQ was not the first liquid detergent that AK offered for the market. In fact, Spark, the earlier form of AK's liquid detergent was available before 2010. However, its performance at the market was not impressive enough. In 2009, AK finally decided to launch a new liquid detergent that can not only replace Spark, but also lead the market. In order to do so, they first formed a task force team, entitled 'Creative Workshop' including the members of marketing, design, R\&D, PR, and sales team, thereby bringing in every resource that AK was able to utilize. After establishing the TFT, 
what they did first was to conduct a series of consumer research. It was carried out at two different regions, first at Europe who led the laundry detergent market at that time and second at Korea, the domestic market.

As the first step of consumer analysis, AK team visited 30 stores from small retail businesses to large retail store in four European countries to examine laundry detergent on the market. To collect more detailed information about acceptance and use of EU consumers, they made in-depth interviews with employees knowledgeable of changes in the market environment. In order to inspect washed clothes and suppliers of laundry room, they literally visited real houses in Europe. In this process, they learned how much liquid detergent that each laundry needs and what the consumers require as they handle and store liquid detergent. At the same time, they strived to gain insights into the domestic detergent market. AK team made in-depth market investigation through visiting their consumers home. It was useful in identifying customers' unmet needs. Also, they conducted Focus Group Discussion and quantitative survey to better understand consumer behavior.

Through the consumer research that the TFT has conducted, they noted four practical concerns. First, consumers disliked their laundry room messy. Second, they had difficulties in measuring how much detergent they wished to use. Third, the consumers preferred to carry rela- tively lighter box of detergent. Finally, the TFT found out that the consumers have been aware of environmental problems, wishing to buy ecofriendly products. These concerns, which are closed related from one another, led the TFT to pay attention to the overall shape, weight, and material of their product and package, allowing the consumers to use the product with an easy, neat, and conscientious way.

Based upon these findings, the TFT proposed the core brand value of its coming product as 'Simple Life, Save Earth.' Three product concepts for developing a new liquid detergent, then, were created by the brand value. First their product needed to be economical. Second, it must be easy to use. Finally, the product needed to be environmental friendly. These three concepts, again, are related from one another. The brand value along with three product concepts, finally, propelled to create the new product, LiQ.

In $L i Q$, these three concepts were realized in two ways: first improving the quality of the liquid detergent, and second putting it in an innovative package. LiQ was a highly concentrated liquid detergent created in the form of gel. The type of detergent allowed the consumers to cut down the amount of detergent, while effectively utilizing the detergent and efficiently spending their money. This also led the product more environmental friendly. At the same time, the gel type detergent provided an impression that it had more power to $\mathrm{re}^{-}$ 
move heavy duty stains and dirt, while dissolving easily in cold water. Consumers could find small, red and blue bids floating in LiQ, believing that they helped to improve the washing power.

The signs of AK's innovative package design are found in a number of ways as well. First, their package design involves three different shapes of lids: overcaps, magiccaps, and pumpcaps. Although the shapes of these caps are different from one another, they all provide easiness, efficiency, convenience, and eco-friendliness when the consumers use and measure LiQ. For example, the overcap lid was designed to pour the detergent into the cap, putting it straight into the washing machine while the magiccap lid was used in a relatively smaller container, simply squeezing out the right amount of detergent. The pumpcap, which was used in a transparent container, allows the consumers to predict their next purchase (Figure 3).
Second, AK paid greater attention not only to the shapes of the lids that they used, but also to the materials that they employed. Before the production of LiQ, AK used PE for the major material for their detergent package. However, in searching for more eco-friendly material, AK replaced PE with PET as they produced the package for LiQ. This new material provided more resilience to the package, thereby adding more convenience and functionality for the consumers. At the same time, this new material can be recycled numerous times, thereby helping environment. AK would like to let their consumers know that they were well aware of the environmental issues. Subsequently, they placed two markings on the package of LiQ, first the carbon label and second environmental friendly certificate. Both markings were accredited by Korea Environmental Industry \& Technology Institute (KEITI).

〈Figure 3〉 Innovations in product package of LiQ
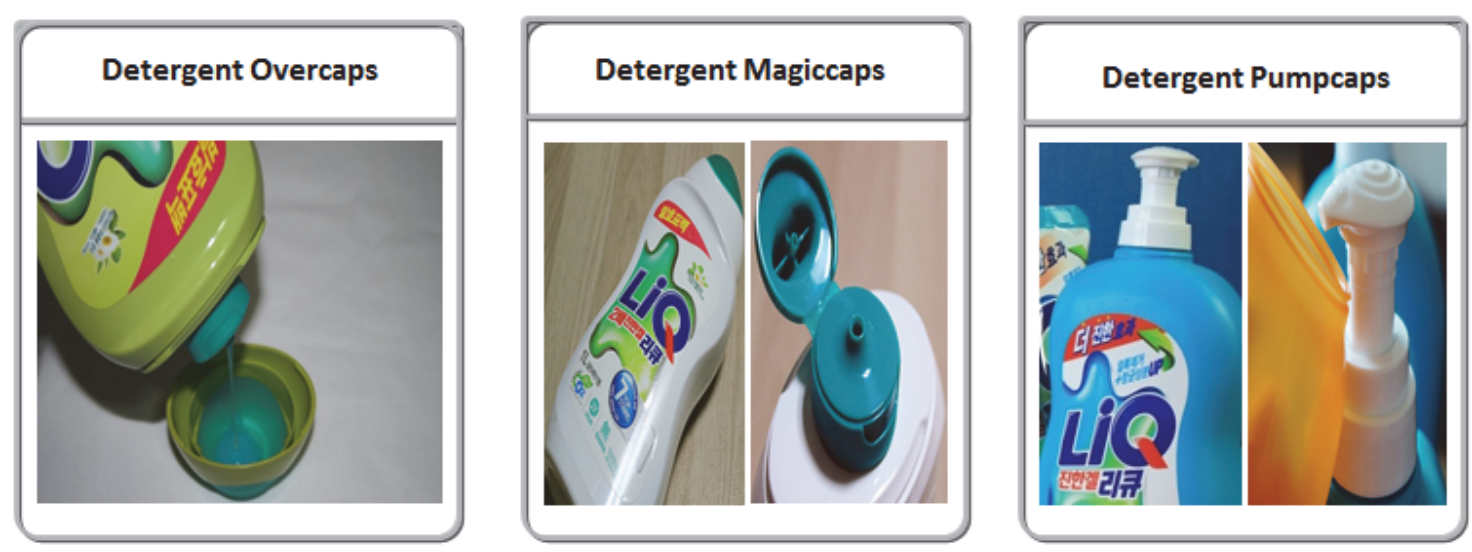


\subsubsection{Performance of $L i Q$}

AK's efforts to lead the liquid detergent market appeared to be properly rewarded. $L i Q$ is now one of the leading liquid detergents in the domestic market. After LiQ launched, it continued to do well, with a record 5\% market share in the 8 weeks and 10\% market share in the 16 weeks, compared with other products that usually spend at least 40 weeks to reach 5\% market share in overall market. Interestingly, just 12 months since its release in May 2010, $\mathrm{LiQ}$ ranked top of liquid detergents in terms of market share and, in December 2012, recorded the highest market share in liquid detergent industry ever. LiQ took top spot ahead of Tech and Act'z, posting the fastest increase in market share and ranking first within a year on the household products market (Figure 4).

\subsection{Gift Sets}

\subsubsection{Market Situation of Gift Sets}

Gift set market in Korea can be divided into a gift set with edible items and with non-edible items, such as bath items. The edible set held the market share of over $80 \%$ of the overall gift set sales, while the remaining $20 \%$ came from bath item gift sets. After the New Year of 2012, bath item gift set had continued to decrease. If we compare the sales of New Year between 2012 and 2013, the number of sales moves from 108.2 to 100.4 billion won. Likewise, a comparison between the sales of Chuseok of 2012 and 2013 shows a similar

〈Figure 4〉 Market share of liquid detergent

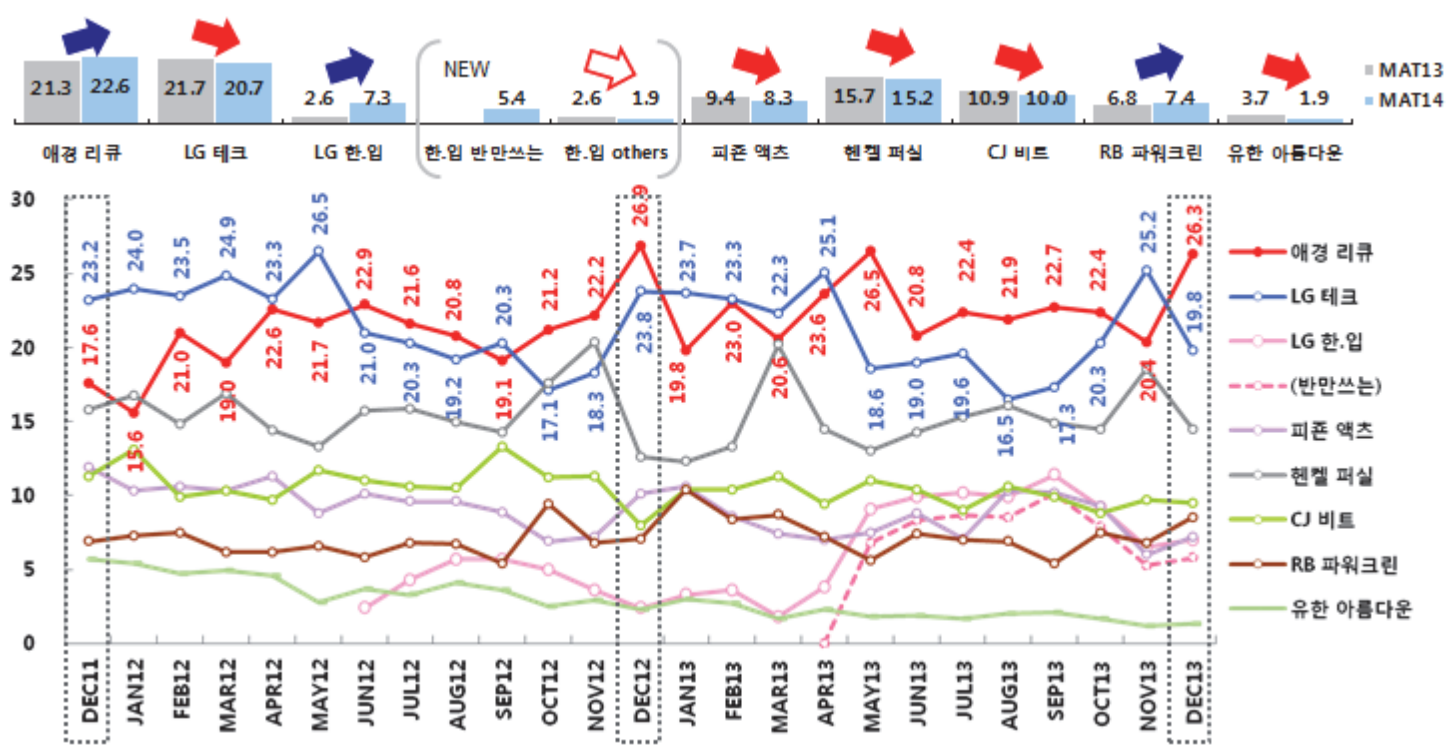

98 ASIA MARKETING JOURNAL Vol. 16 No. 04 January 2015 
result. However, interestingly enough, despite the decrease of non-edible gift sets, the most recent record, that is, the gift set market of Chuseok in 2013, shows that the total sales reached to be worth almost 569.9 billion won. The number consists of 459.9 billion won from edible gift sets and 110.0 billion won from the bath item gift sets (Figure 5). It means that the growth rate of overall gift set market was up by $2.5 \%$ over a year ago. In other words, contrary to the market for bath item gift sets, which was reducing, the overall gift set market has been gradually expanded because edible gift sets market increases.

Figure 6 exhibits that AK's market share rapidly went down from $16.9 \%$ to $13.2 \%$ during the one year time period of Chuseok 2011 to Chuseok 2012. It seemed that the gift set market was not an ideal place for AK to com- pete with other companies including LG and Amore Pacific (AP thereafter). AK analyzed a number of reasons for downsizing the bath item gift set. First of all, retail sales were chilled by a recession that shaded Korea longer that it first expanded. Second, law legislation that regulates the business hours in Korea's large discount stores or large-scale super supermarkets (SSMs) has become valid. Third, excessive competition of companies and lower priced products that their price had never been examined and analyzed all led the gift set market static and even sluggish. This resulted in low consumer confidence, thereby not purchasing the gift sets.

AK also learned that most buyers bought bathrelated gift sets because they were attracted by their affordable price and functionality. Also, they assumed that every household was in need

〈Figure 5〉 Total sales of gift sets

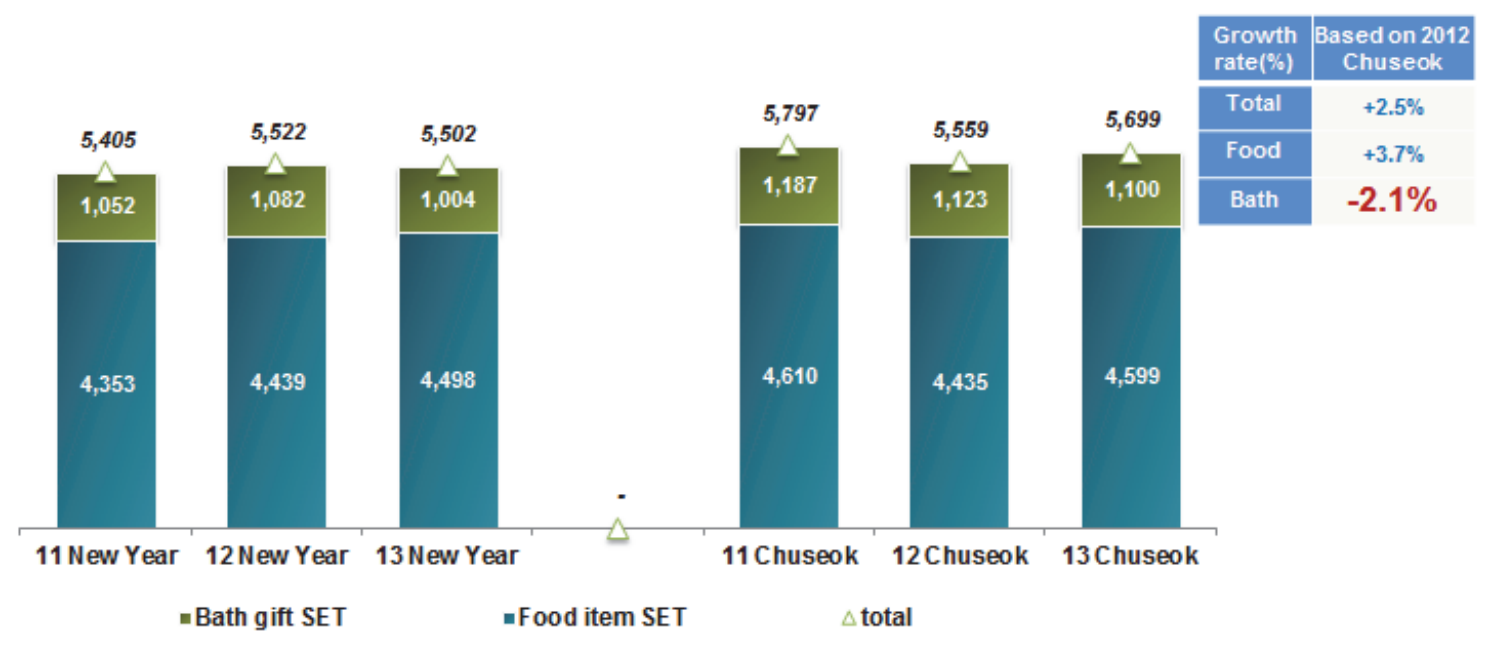

(hundred million won) 
〈Figure 6〉 Market share of bath item gift sets: Discount stores POS system

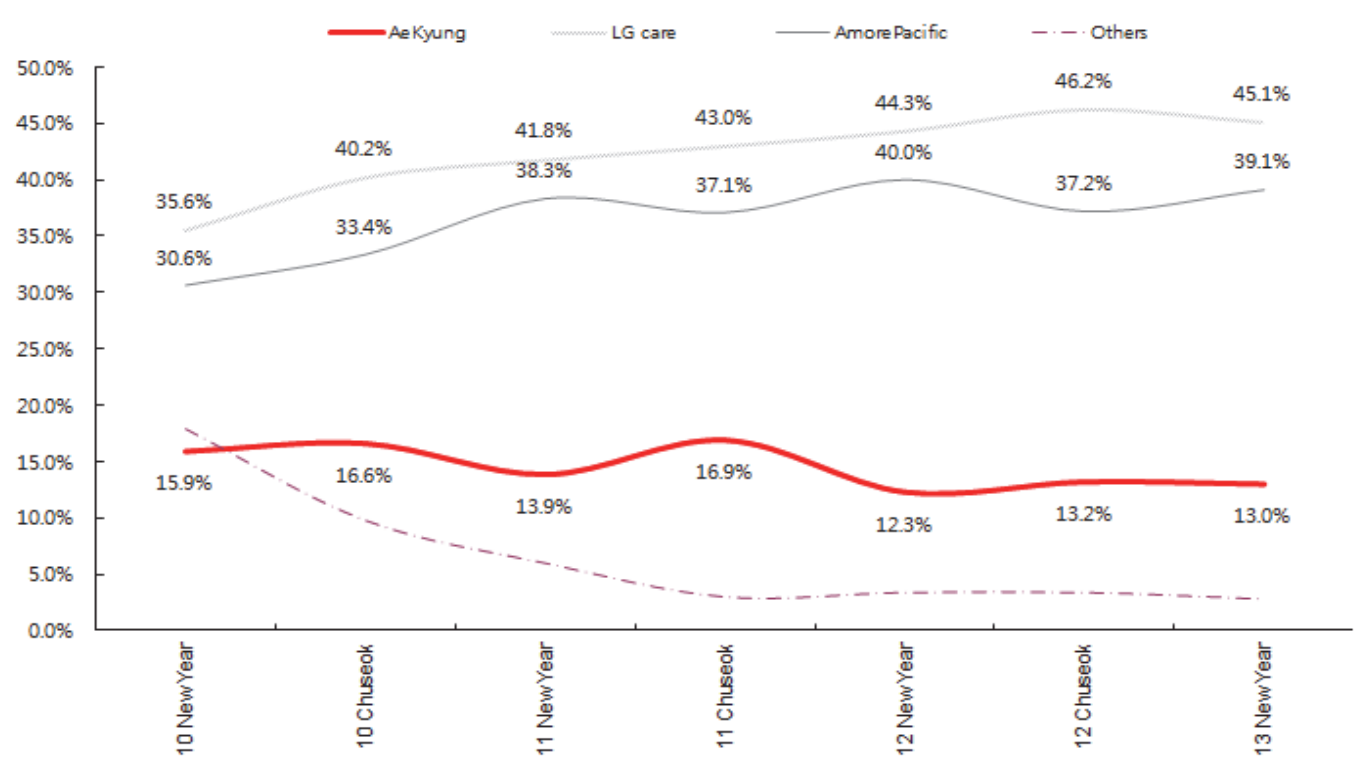

of bath-related items. Gift buyers, therefore, This result can be read that the gift set reconsidered bath item gift sets to be some of ceivers are now considering less of a necessity the ideal presents that they could give out. of the bath-related items. The gift receivers However, the surveys from year 2007 and 2011 even testified that the bath item gift sets were shows that, when comparing 2007 with 2011, the goods that they least wanted. Because these the average household had almost twice as much products are found in every household, they do inventory of Shampoo, Toothpaste, Soap, and other daily household products in 2011 (Figure 7). meaning attached to them.

〈Figure 7〉 Household inventory stock of bath items

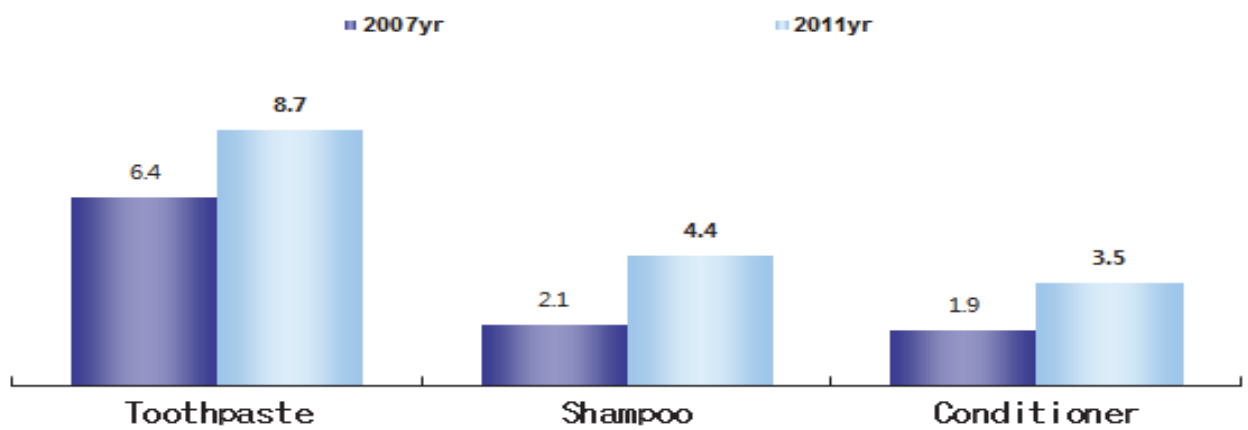

100 ASIA MARKETING JOURNAL Vol. 16 No. 04 January 2015 
After AK had found out various reasons of why bath item gift sets are not able to attract the gift buyers any more, they have begun to design their marketing strategies. These involved how to appeal to consumer's sentimental value through their bath item gift sets, how to attach special meaning to them, and finally how to differentiate their product from the competing products. The following chapter will deal with more detailed marketing strategies on AK's part, illustrating what they have done to develop new bath item gift sets.

\subsubsection{New Product Development of Gift Sets}

One of the problems that AK faced, when they aimed to develop bath item gift sets, was that they did not have a clear brand concept associated with them. Absence of brand identity also meant that AK had difficulties in terms of distinguishing their products from others. What AK needed to do, therefore, was to develop strategies and identities that could differentiate them from other competitors. To solve this problem, AK turned their attention to the design of their gift sets. AK, even before they have begun to develop a new identity for gift sets, was well aware of the significance that was attached to a product's design. They knew that an innovative design itself could become a hallmark of the company's identity, leaving a strong impression on consumer's part.
For AK, looking for an innovative design for their gift sets was important. But, at the same time, reading trend of Korean society was also crucial for them to realize the design concept in their products. Based upon the current trend that runs through Korean society, AK proposed three product concepts that both fulfill the consumers' need while becoming the identity for their gift sets. These three product concepts are following; first Nostalgia, second Healing, and finally third Frugality (Figure 8).

The product concept, Nostalgia, reflects recent trend read in the age group of 40s and 50s, who was constantly looking back. These generations were looking for products that could lead them to the old days, bringing in various types of memories that they had. These memories allowed them to forget about the reality for a moment while being nostalgic about the memories of old, beautiful days.

To realize the product concept of Nostalgia, AK was researching for proper images that could arouse the consumer's memories. To do so, AK looked for old, classical movies, the mediums that could inspire and motivate various types of memories for every generation. The movie, Roman Holiday was a good example. In particular, AK hoped to capture the images of movie stars in their gift set products, the stars including Audrey Hepburn and Marilyn Monroe. Classic movie stars were not the only images that AK hoped to reproduce in their products. The images of Beetles and ABBA, the pop singers who repre- 
sented 1970s and 1980s pop music, were also used in order to attract the targeted consumers.

Healing was also an important concept and trend that is found in every aspect of Korean society. Consumers were tired of extreme competition, pressure from peer groups, anxiety from economic issues, and long lasting recessions. It appeared that consumers reached a certain point that they did not seem to be bothered by them. In other words, they wanted to hide from the reality, finding a healing in various aspects and places of their lives. Consumers sometimes could be extremely adventurous. Often, they were willing to explore uncharted territories, visiting lesser known or unknown places. Or, they would like to separate themselves from their real lives, only enjoying what they have, see, and feel.

The concept of healing was met by reproducing well-known, familiar art works in AK's gift set products. For the purpose, Van Gogh, who was known for painting various types of French country scenes, was chosen. AK hoped to draw upon their consumers' attention to Gogh's paintings, while appreciating his amazing works. AK was aware of the fact that while their consumers were attracted to the images of paintings, they could feel that some sort of healing was taking place.

Finally, Frugality was the concept that AK wished to set up as they develop the new sets. This concept, in fact, has less to do with consumers' emotion and sensibility, but more to do with influences from outside. For example, economic recessions that prolonged Korean society longer that it had expected were some of the hidden factors that led consumers to be frugal. Customers became more price sensitive, thereby buying less expansive products. Without scarifying the quality of the product, they were looking for reasonably priced products with attractive outlook. For these consumers, attractive and elegant product design, definitely, matters.

〈Figure 8〉 Three product concepts and package design of AK's gift sets
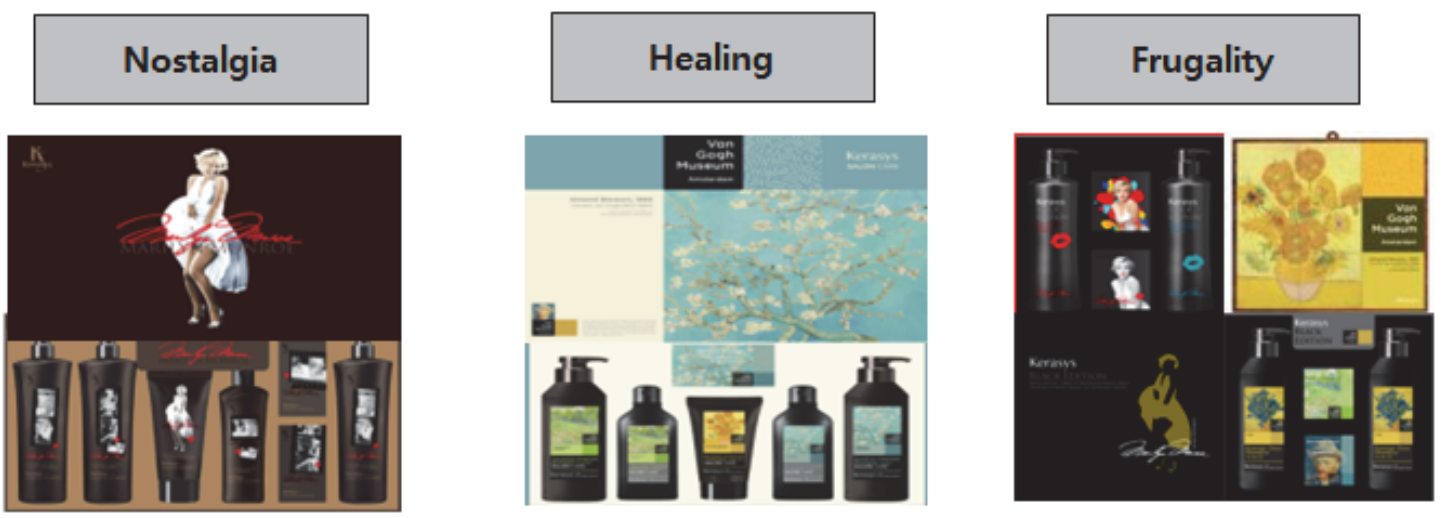
In order to realize the concept of Frugality in AK's product design, they referred to other luxurious gift sets. AK launched gift sets called “Kerasys' Black Edition," and "Kerasys Perfume Edition." Without doubt, the term, Black, in a sense, stands for luxurious, high end product while the term, Perfume, also reminding us of luxurious goods. In other words, what AK did was to borrow these ideas from luxurious goods, applying them directly to their bath item gift sets. At the same time, AK redesigned the package of these sets, adding elegance and beauty that, eventually, led the consumers felt as though they were buying truly luxurious gift sets.

\subsubsection{Performance of AK’s Gift Sets}

It seems that AK's marketing strategies that involve product design innovation directly changes both the total sales and the market share of AK's bath item gift sets. The total sales of 2012 Chuseok was 19,840 million won. But the number increases to 22,320 million won in 2013 Chuseok. Likewise, the total sales of New Year changes from 14,322 to 17,245 million won in 2013 and 2014 respectively, demonstrating significant increases. This points to a conclusion that the introduction of new bath item gift set launched right after New year of 2013 directly influenced the total sales and profit (Figure 9). We can observe the similar result from the market share as well. Comparing the market shares of Chuseok in 2012 and 2013, the number moves from $13.2 \%$ to $17.0 \%$, pointing out $24 \%$ of increase (Figure 10). This change, again, was possible because AK produced redesigned bath item gift sets according to the three concepts that this paper illustrates after New Year of 2013.

〈Figure 9〉 Total sales and profit of AK's gift sets

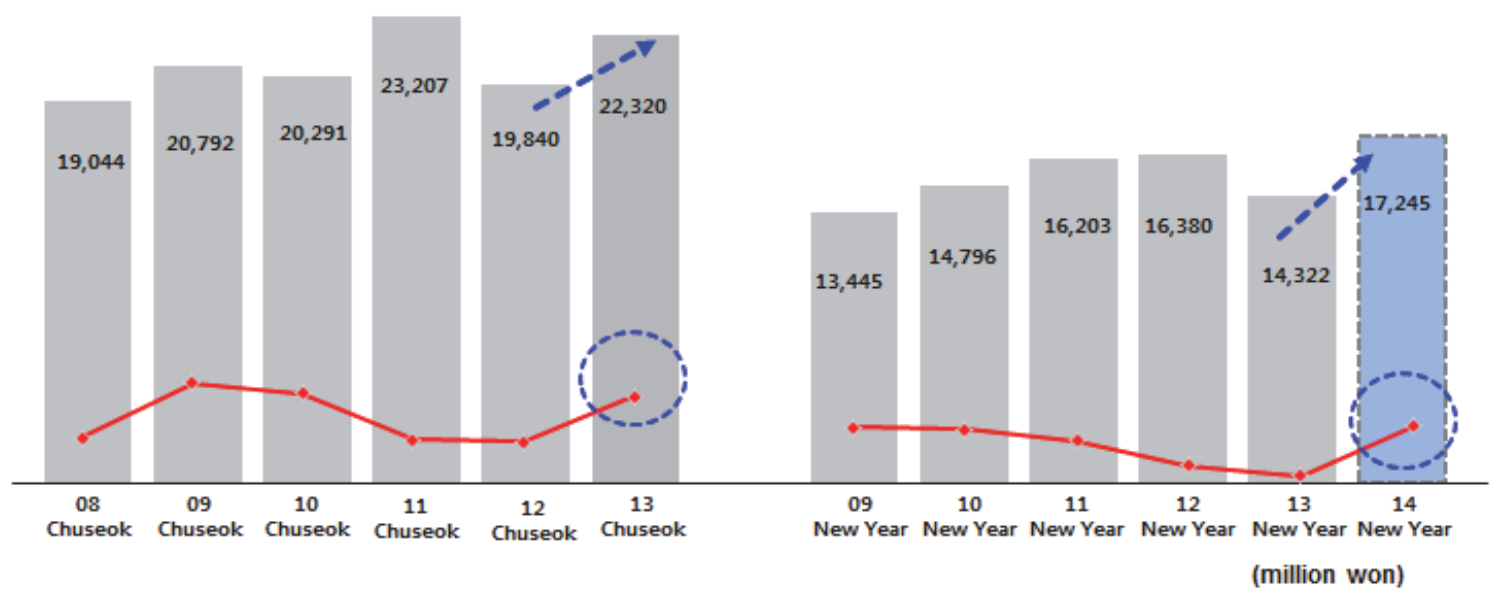

Aekyung: Design Innovation on New Product Development 103 
〈Figure 10〉 Total market share of AK's gift sets

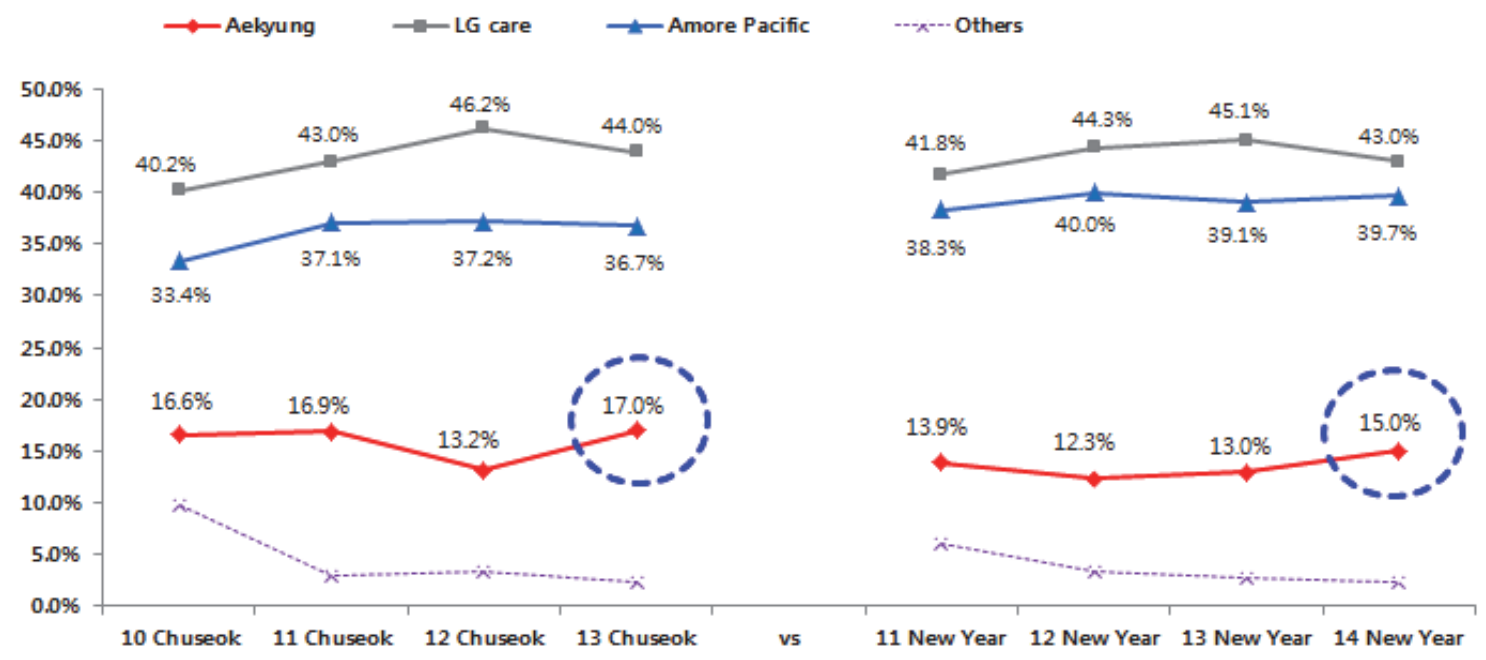

\section{Conclusions}

Based on love and respect, the values that AK has set out as they first established their company in 1954, AK has constantly and continuously encouraged and supported design innovation. In order to achieve the innovation, AK's management philosophy of creativity and communication played fundamental as well as practical role. The Design Center that manifests AK's philosophy was a good example. It actively participates in developing and improving almost every product AK has produced since 2007. These new products with innovative design, in one way another, lead various categories of household goods market in Korea.

At the same time, AK's success case through design innovation provides a number of points to consider. First, searching for and implementing an innovative design are rewarding process. It is directly related to the sales of products, instantly showing the market share has expanded (or reduced). The cases of LiQ and bath item gift sets demonstrate this point.

Second, understanding the significance of $\mathrm{de}^{-}$ sign innovation on top management's part is extremely important. Because AK's top management was well aware of the significance of design innovation, they supported the design center throughout. Also, they were willing to wait for the new ideas coming up, encouraging their employees to carefully listen to the consumers' unmet needs.

Third, as AK's case shows, having a positive, democratic corporate culture is very important in creating an innovative design. An innovative design can be discussed more freely in the kind 
of corporate culture. Of course, communication between the members of package development team and creative design team was crucial. Communication between the members of these teams and top management is also important. Without the communication and understanding of each other, an innovative design will not be able to be realized. At the same time, the kind of corporate culture encourages various types of challenges. Again, without these challenges along with the attitude that can overcome failure, an innovation cannot be reached.

〈Received January 9. 2015〉

$\langle$ Accepted January 16. 2015〉

\section{References}

Gotzsch, J. (1999), “Design Orientation in New Product Development," in Jerrard, B., Newport, R. and Trueman, M. (Eds), Managing new product innovation, London, Taylor and Francis.

Ravasi, D. and I. Stigliani (2012), "Product Design: A Review and Research Agenda for Management Studies," International Journal of Management Reviews, 14(4), pp. 464488.

Swan, K.S., M. Kotabe and B. B. Allred (2005), "Exploring Robust Design Capabilities, Their Role in Creating Global Products, and Their Relationship to Firm Performance," Journal of Product Innovation Management, 22(2), pp. 144-164. 